\title{
Comparison of Measurements of Corpus Callosum in Formalin Fixed Brain and in Magnetic Resonance Imaging Scan
}

\section{ABSTRACT}

Introduction: Corpus callosum is the collection of white fibres situated in the longitudinal fissure of brain connecting the two halves of the brain. Different methodologies may yield different results in the measurement of diameters of corpus callosum.

Aim: To find out any difference in corpus callosum diameters when these diameters were measured in formalin fixed brain specimens and in Magnetic Resonance Imaging (MRI) scans.

Materials and Methods: This was a cross-sectional study carried out in the Department of Anatomy, Silchar Medical College and Hospital, Silchar, Assam, India from April 2014 to March 2019. A total of 107 formalin fixed cadaveric brain specimens were used to measure length, height and thickness of corpus callosum and MRI scans of 43 patients were used to measure the same diameters. The mean value of all the diameters of corpus callosum measured in formalin fixed brain specimens and in MRI scans were compared. Statistical significance was calculated with student's t-test and $p$-value $<0.05$ was considered significant.

Results: Total data collected from 107 brain specimens (66 were males and 41 were females) and MRI scans of 43 subjects (30 were males and 13 were females), all in age range of 1070 years, were analysed. Mean values of length, height, midbody, rostrum and splenium thickness of corpus callosum in cadaveric brain specimens were recorded $70.85 \mathrm{~mm}, 23.37 \mathrm{~mm}$, $5.46 \mathrm{~mm}, 5.91 \mathrm{~mm}$ and $8.40 \mathrm{~mm}$, respectively and same diameters in MRI scans were $74.61 \mathrm{~mm}, 25.85 \mathrm{~mm}, 5.84 \mathrm{~mm}$, $6.68 \mathrm{~mm}, 10.46 \mathrm{~mm}$, respectively. Difference of these diameters of corpus callosum measured in cadaveric brain specimens and in MRI scans was statistically significant with $p$-value $=0.0001$ for length, 0.0006 for height and 0.0001 for thickness.

Conclusion: Significant difference was observed when the same diameters of corpus callosum were measured in MRI and in formalin fixed cadaveric brain specimens.

Keywords: Height, Length, Rostrum, Splenium, Thickness

\section{INTRODUCTION}

Corpus callosum is the collection of white fibres situated in the longitudinal fissure of brain which acts as inter-hemispheric fibres connecting the two halves of the brain and is responsible for distribution of information between homotropic areas of two brain hemispheres. Corpus callosum's primary role is the incorporation and relaying of information between brain hemispheres and the processing of sensory, motor and cognitive information [1].

Fibres in the corpus callosum allow impulses to pass from one half to the other half of the brain and thereby assure that the left and right hemispheres can work cooperatively [2]. Different parts of corpus callosum from anterior to posterior are rostrum, genu, body or trunk and splenium [3].

Different diameters of corpus callosum were studied by using either cadaveric brain fixed in formalin or MRI scans and one study even used fresh brains for such measurements [4]. Thus, different approaches (that is corpus callosum measurement in formalin fixed brain, fresh brain and MRI) conducted for measurement of corpus callosum may produce different results [4]. The two approaches, MRI and study on cadaveric brain are radically different each having its own advantages and disadvantages [4]. Goncalves-Ferreira AJ et al., reported distortion of corpus callosum diameters on removal from cranial cavity [5]. When the corpus callosum parameters are studied in autopsied brain, there may be chance of change in corpus callosum morphology during removal of brain from cranial cavity or due to tissue changes or due to fixation techniques, but these changes can be eliminated when corpus callosum is studied in in-vivo MRI scans. However, $\mathrm{MRI}$ studies have been criticised since they may not give adequate brain size correlates and can produce varying results depending on methodological procedure used [6]. Therefore, it is relevant to know whether cadaveric brain-based data can be extrapolated for clinical comparisons.

In the present study, comparison was made between measurements of different parameters of corpus callosum in formalin fixed brain specimens and in MRI. These findings will be useful for neurosurgeons for planning of callosotomy or other brain ventricular surgeries.

\section{MATERIALS AND METHODS}

This was a cross-sectional study carried out from April 2014 to March 2019, after taking the Ethical Committee clearance. Total of 107 brain specimens were obtained from the cadavers voluntarily donated to the Department of Anatomy, Silchar Medical College and Hospital, Silchar and also from the dead bodies subjected to postmortem examinations in the Department of Forensic Medicine, Silchar Medical College and Hospital, Silchar, Assam, India. Out of 107, 66 were male and 41 were female brains of different age groups.

Sample size calculation: It was done by formula $n=z^{2} \sigma^{2} / d^{2}$, where $z$ is the level of confidence desired, $d$ is the desired width of the confidence interval, $\sigma$ is the standard deviation. Standard deviation is estimated from previous studies [4,5]. The brains were removed from the cranial cavity, labelled and were preserved in $10 \%$ formalin solutions.

Inclusion criteria: Only those brains with no visible gross abnormalities were included in the study. MRI scans with normal anatomy of brain and corpus callosum of the patients were included in the study.

Exclusion criteria: The brain specimens from people with intracranial lesions, head injury or recorded brain pathology were 
excluded from the study. MRI scans with any visible mass, pathology or any abnormalities which could cause distortion of normal anatomical structure of brain and corpus callosum were excluded from the study.

Brains were sectioned in sagittal plane from front to back through the septum pellucidum. Different diameters of the corpus callosum were measured with digital vernier calliper and all the measurements were recorded in millimetre $(\mathrm{mm})$.

Following measurements were recorded using digital slide calliper:

1. Length of corpus callosum was recorded as follows:

- Anterior most point to posterior most point of corpus callosum (EZ) i.e., longitudinal diameter of corpus callosum (Point ' $E$ ' is anterior most point of corpus callosum and point ' $Z$ ' is posterior most point of corpus callosum) [Table/Fig-1] [7].

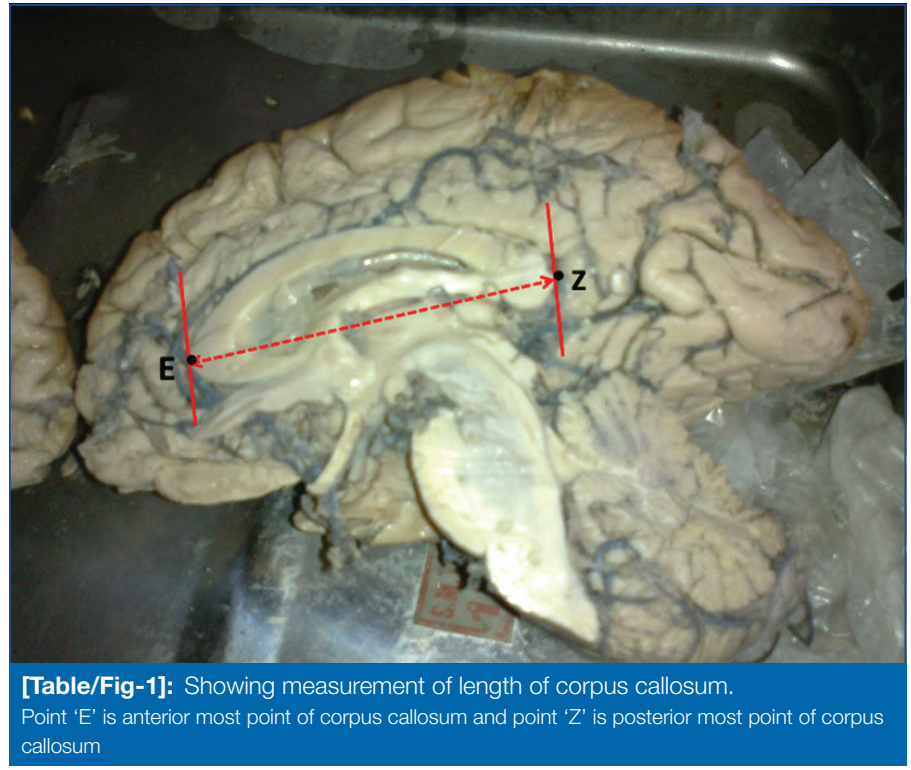

\section{Height $(\mathrm{H})$ of corpus callosum was measured as follows:}

- $\quad$ Point ' $T$ ' is highest point on the superior border of corpus callosum [4].

- $\quad$ Point ' $R$ ' is inferior most point on the rostrum.

- Point ' $S$ ' is inferior most point on the splenium.

A horizontal line was taken through the inferior-most points of rostrum (R) and splenium (S); another line parallel to this was taken through the highest point (T) of corpus callosum; distance between these two lines was recorded as height of corpus callosum [Table/Fig-2].

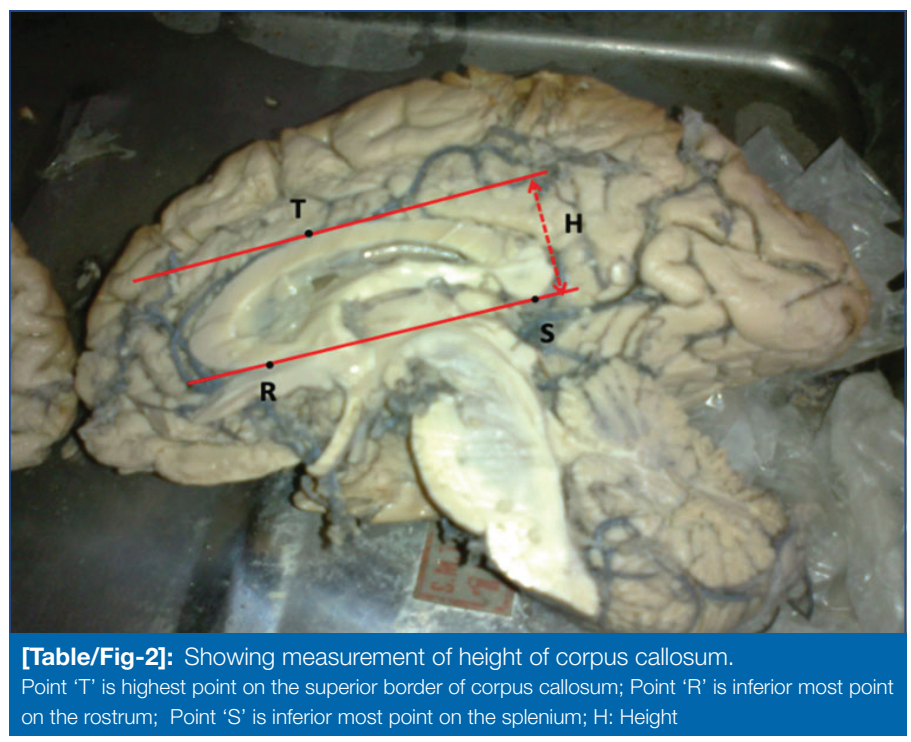

\section{Thickness of corpus callosum was recorded as follows:}

- WM, thickness of body at the midpoint of corpus callosum. Midpoint will be taken at half the longitudinal diameter of corpus callosum.

- WR, maximum thickness of rostrum of corpus callosum [4].

- WS, maximum thickness of splenium of corpus callosum [4] [Table/Fig-3]. All the measurements on brain specimens by vernier calliper is shown in [Table/Fig-4].
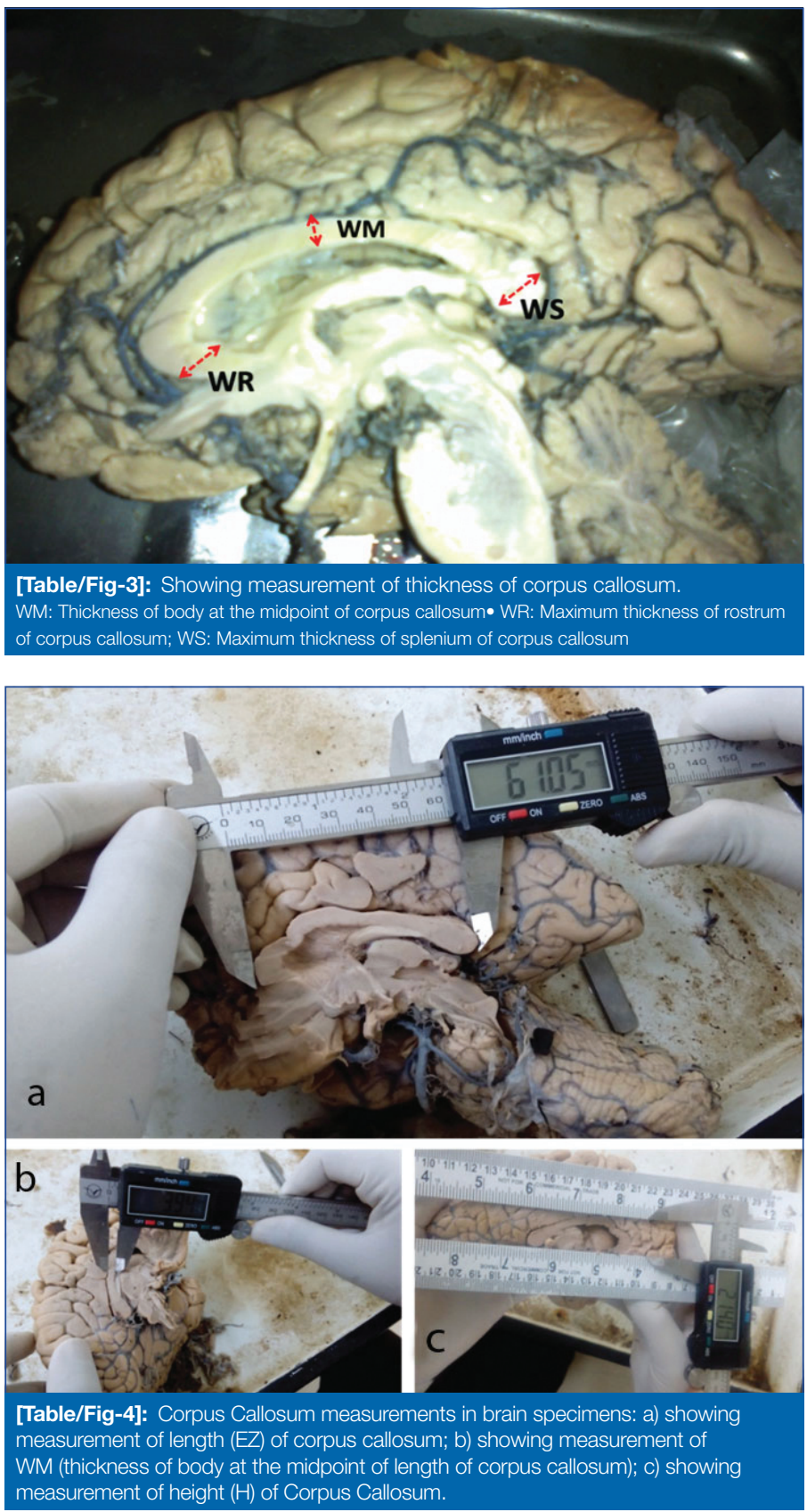

For comparison of the measurements of corpus callosum in cadaveric brain specimens with similar measurements in radiological images, $\mathrm{MRI}$ (magnetic resonance imaging) scans of the patients (they were live patients who were referred to Radiology Department of Silchar Medical College and Hospital for MRI investigation and not the same patients from whom the brain was considered) were collected. MRI scanning was performed in the Siemens Avanto Fit 1.5 tesla machine in the Department of Radiology, Silchar Medical College and Hospital. Sagittal and coronal axial planes were used in the MRI scanning. A total of 43 patient's MRI scans were carried out to measure the diameters of corpus callosum, out of which 30 were male and 13 were female patients of different ages. MRI scans were reviewed by the Radiologists of the Department of Radiology, Silchar Medical College and Hospital [Table/Fig-5]. 

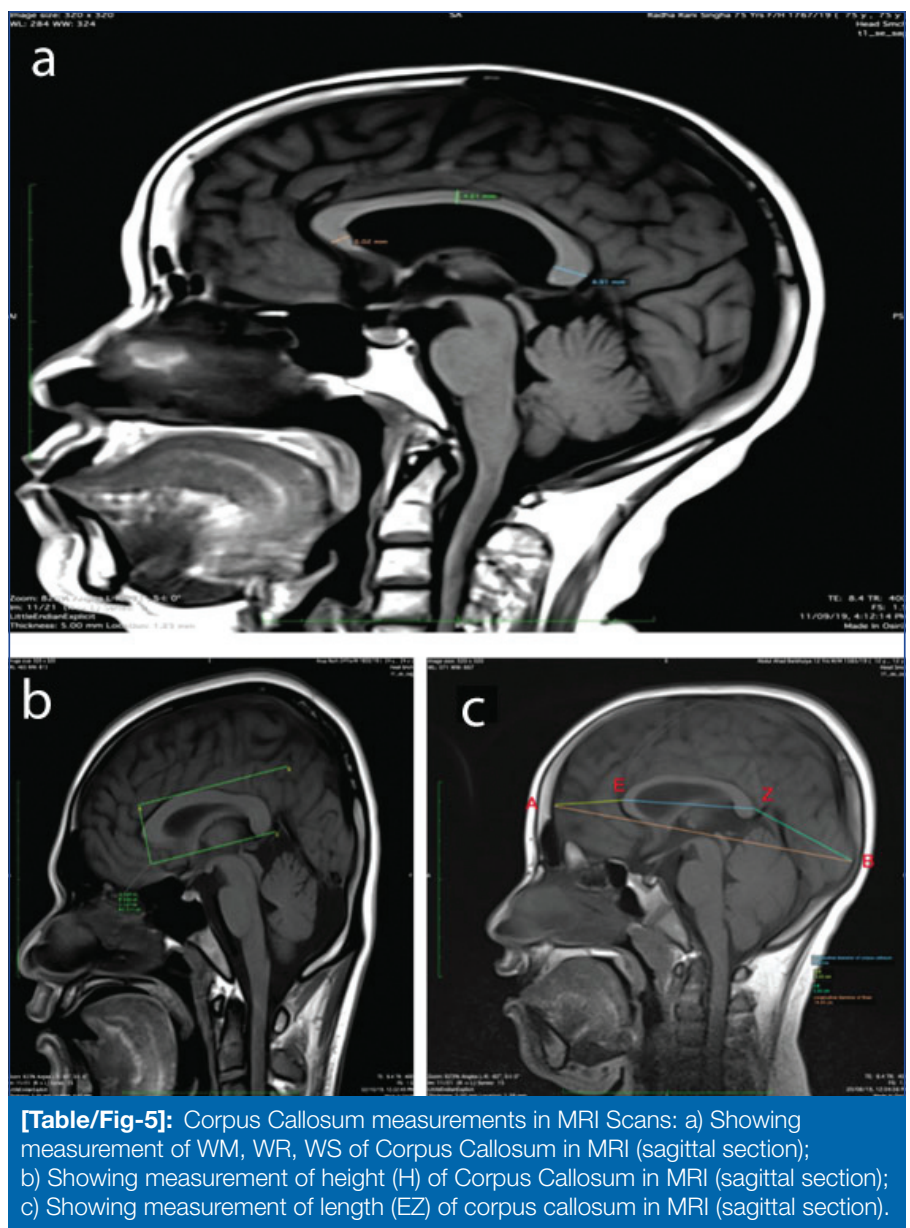

\section{STATISTICAL ANALYSIS}

The data obtained after measurements of different parameters as described were tabulated and analysed statistically using statistical software Statistical Package for Social Sciences (SPSS) version 18.0. version 18. Student's t-test was used for test of significance and level of significance was considered to be 0.05 for $p$-value.

\section{RESULTS}

Total number of 107 brain specimens were collected and EZ, $\mathrm{H}$, WM, WR, WS diameters were measured with digital vernier calliper; measurements were recorded, tabulated and analysed. Out of 107 brain specimens, 66 were male and 41 were female brains of different age groups with percentage of $61.68 \%$ and $38.32 \%$, respectively. 43 patient's MRI scans were carried out to measure the EZ, H, WM, WR and WS diameters of corpus callosum, out of which 30 were male and 13 were female patients of different ages. The total sample of brain specimens and MRI patients were within age range of 10-70 years of age.

On measurement of different diameters of corpus callosum in preserved brain specimen, average length of corpus callosum was found to be $70.85 \mathrm{~mm}$ with range from $58.98-87.26 \mathrm{~mm}$ and average height of corpus callosum was found to be $23.37 \mathrm{~mm}$ with range from 16.89-29.42 mm. Also, average widths of corpus callosum at mid-body, rostrum and splenium were recorded $5.46 \mathrm{~mm}, 5.91 \mathrm{~mm}$, $8.40 \mathrm{~mm}$, respectively [Table/Fig-6].

While, on measurement of different diameters of corpus callosum in MRI scans, average length and height of corpus callosum were found to be $74.61 \mathrm{~mm}$ and $25.85 \mathrm{~mm}$, respectively and average widths of corpus callosum at mid-body, rostrum and splenium were $5.84 \mathrm{~mm}, 6.68 \mathrm{~mm}, 10.46 \mathrm{~mm}$, respectively [Table/Fig-7].

In case of measurements of different diameters of corpus callosum, average antero-posterior length of corpus callosum (EZ) was found to be more when measured with MRI than the cadaveric brain measurement and the difference was statistically extremely significant with $p$-value 0.0001 [Table/Fig-8,4,5].

\begin{tabular}{|c|c|c|c|c|c|}
\hline \multirow{3}{*}{$\begin{array}{l}\text { Statistical } \\
\text { values }\end{array}$} & \multicolumn{5}{|c|}{ Parameters of corpus callosum in cadaveric brain specimens) } \\
\hline & \multirow{2}{*}{$\frac{\text { Length }(\mathrm{mm})}{\mathrm{EZ}}$} & \multirow{2}{*}{$\frac{\text { Height }(\mathrm{mm})}{\mathrm{H}}$} & \multicolumn{3}{|c|}{ Thickness (mm) } \\
\hline & & & WM & WR & ws \\
\hline Mean & 70.85 & 23.37 & 5.46 & 5.91 & 8.40 \\
\hline Median & 72.13 & 23.50 & 5.26 & 5.78 & 8.33 \\
\hline SD & 6.52 & 2.62 & 1.03 & 1.02 & 1.09 \\
\hline Minimum value & 58.98 & 16.89 & 3.79 & 4.1 & 6.1 \\
\hline Maximum value & 87.26 & 29.42 & 8.56 & 8.53 & 12.11 \\
\hline \multicolumn{6}{|c|}{$\begin{array}{l}\text { [Table/Fig-6]: Showing statistical values of different parameters of corpus callosum } \\
\text { in cadaveric brain. } \\
\text { SD is standard deviation; EZ: Longitudinal diameter of corpus callosum; H: Height of corpus } \\
\text { callosum; WM: Thickness of body at the midpoint of corpus callosum; WR: Maximum thickness } \\
\text { of rostrum of corpus callosum; WS: Maximum thickness of splenium of corpus callosum }\end{array}$} \\
\hline
\end{tabular}

\begin{tabular}{|l|c|c|}
\hline \multirow{2}{*}{ Corpus callosum parameters } & \multicolumn{2}{|c|}{ Measurements in MRI } \\
\cline { 2 - 3 } & Mean $(\mathrm{mm})$ & $\mathrm{SD}(\mathrm{mm})$ \\
\hline EZ & 74.61 & 6.38 \\
\hline H & 25.85 & 4.85 \\
\hline WM & 5.84 & 1.35 \\
\hline WR & 6.68 & 2.48 \\
\hline WS & 10.46 & 1.79 \\
\hline
\end{tabular}

[Table/Fig-7]: Showing mean values and standard deviations of different parameters of corpus callosum of the patients measured in Magnetic Resonance Imaging (MRI) (EZ: Longitudinal diameter of corpus callosum, H: Height of corpus callosum, WM: thickness of body at the midpoint of corpus callosum, WR: Maximum thickness of rostrum of corpus callosum, WS: Maximum thickness of splenium of corpus callosum).

\begin{tabular}{|l|c|c|c|}
\hline \multirow{2}{*}{$\begin{array}{l}\text { Corpus callosum } \\
\text { parameters }\end{array}$} & $\begin{array}{c}\text { Measurements } \\
\text { in MRI }\end{array}$ & $\begin{array}{c}\text { Measurements in cadaveric } \\
\text { brain specimens }\end{array}$ & \multirow{2}{*}{ p-value } \\
\cline { 2 - 3 } & Mean $(\mathrm{mm})$ & Mean $(\mathrm{mm})$ & $0.0001^{*}$ \\
\hline EZ & 74.61 & 70.85 & $0.0006^{*}$ \\
\hline H & 25.85 & 23.37 & 0.199 \\
\hline WM & 5.84 & 5.46 & 0.061 \\
\hline WR & 6.68 & 5.91 & $0.0001^{*}$ \\
\hline WS & 10.46 & 8.40 &
\end{tabular}

[Table/Fig-8]: Showing mean values of different parameters of corpus callosum measured in MRI and in cadaveric brain specimens with $\mathrm{p}$-values of the comparison of parameters (EZ: Longitudinal diameter of corpus callosum, H: Height of corpus callosum, WM: Thickness of body at the midpoint of corpus callosum, WR: Maximum thickness of rostrum of corpus callosum, WS: Maximum thickness of splenium of corpus callosum). *Statistically significant. Statistical test used: student's t-test.

In case of measurement of height of the corpus callosum, the average value of callosal height was found to be more when measured in $\mathrm{MRI}$ than the cadaveric brain measurement and the difference was statistically extremely significant with p-value 0.0006 [Table/Fig-8,4,5].

Average value of thickness of corpus callosum's mid-body (WM) was found only $0.38 \mathrm{~mm}$ more when measured in MRI than the cadaveric brain measurement and also the difference was not statistically significant with p-value 0.199 [Table/Fig-8,4,5].

Both the average value of maximum thickness of rostrum and splenium of the corpus callosum were observed to be more when measured with $\mathrm{MRI}$ than the cadaveric brain measurement. But this difference of $\mathrm{MRI}$ and cadaveric brain measurement in case of rostrum thickness was not statistically significant with $p$-value 0.061 , while the same difference (measurement in MRI and cadaveric brain) in case of splenium thickness, measurement was statistically extremely significant with p-value 0.0001 [Table/Fig-8,4,5].

Thus, in the present study, significant difference was observed when the same parameters of corpus callosum were measured in $\mathrm{MRI}$ and in formalin fixed cadaveric brain specimens.

\section{DISCUSSION}

In the present study, average length, height and thickness at different parts of corpus callosum were found more when measured in MRI than the preserved brain specimen measurements. 
Gupta T et al., conducted a comparative study of corpus callosum morphometry on fresh brain, preserved brain and MRI scan and according to them, their study was a unique study which was not performed earlier [4]. They found measurements of all parameters of corpus callosum were more in fresh brain than the preserved brain and MRI images. Maximum width at mid-body, rostrum, splenium and antero-posterior length of corpus callosum were significantly more in fresh brain than the preserved brain and MRI images but the height of corpus callosum though more in fresh brain but statistically non significant. They also noted that similarity was there in the measurements of parameters of corpus callosum's mid-body, rostrum and splenial width in preserved brain and MRI images [4]. They also found that mean values of the corpus callosum's length and height was found to be more in MRI measurement than the cadaveric brain specimen measurement and the difference was found to be statistically significant. Moreover, mean values of the thickness or width of corpus callosum at the mid-body, rostrum and splenium were found be more in MRI measurement than the cadaveric brain specimen measurement. The difference was statistically significant for mid-body and splenium thickness [4].

On the other hand, Goncalves-Ferreira AJ et al., while measuring corpus callosum in preserved brain and MRI, reported mean length of corpus callosum more in preserved brain than the MRI [Table/Fig-9] [5]. But similar to present study, they found mean height of corpus callosum more in MRI than the preserved brain. Comparative evaluation of findings of corpus callosum measurements in previous studies with present study is given in [Table/Fig-9] [4,5].

\begin{tabular}{|l|c|c|c|c|c|c|}
\hline & \multicolumn{2}{|c|}{$\begin{array}{c}\text { Mean length of } \\
\text { corpus callosum } \\
\text { (mm) }\end{array}$} & \multicolumn{2}{|c|}{$\begin{array}{c}\text { Mean height of } \\
\text { corpus callosum } \\
\text { (mm) }\end{array}$} & \multicolumn{2}{|c|}{$\begin{array}{c}\text { Mean width of } \\
\text { splenium of corpus } \\
\text { callosum (mm) }\end{array}$} \\
\cline { 2 - 7 } $\begin{array}{l}\text { Studies and } \\
\text { Place }\end{array}$ & $\begin{array}{c}\text { Preserved } \\
\text { brain }\end{array}$ & MRI & $\begin{array}{c}\text { Preserved } \\
\text { brain }\end{array}$ & MRI & $\begin{array}{c}\text { Preserved } \\
\text { brain }\end{array}$ & MRI \\
\hline $\begin{array}{l}\text { Gupta T et } \\
\text { al., (2008) [4] } \\
\text { (Chandigarh, } \\
\text { India) }\end{array}$ & 69.2 & 74.0 & 20.4 & 30.2 & 10.7 & 11.6 \\
\hline $\begin{array}{l}\text { Goncalves- } \\
\text { Ferreira AJ et } \\
\text { al., 2001 [5] } \\
\text { (Portugal) }\end{array}$ & 87.2 & 74.9 & 19.7 & 25.5 & - & - \\
\hline $\begin{array}{l}\text { Present study } \\
\text { (Silchar, India) }\end{array}$ & 70.85 & 74.61 & 23.37 & 25.85 & 8.40 & 10.46 \\
\hline
\end{tabular}

Oguz I et al., compare the MRI scan images of live and postmortem rat brains and detected no significant changes in volumetric measurements [8]. The data obtained from the study will be useful for neurosurgeons for planning of callosotomy or other brain ventricular surgeries.

\section{Limitation(s)}

In this study, formalin fixed cadaveric brain specimens were used for the measurements of different diameters of corpus callosum and brain. But this preservation with formalin may cause distortion of size and shape of the brain under study which in turn may give altered readings. Moreover $10 \%$ formalin solutions were used to preserve the brain under study, but the quality of formalin supplied by the institution may vary from the supply of other institution.

\section{CONCLUSION(S)}

From the study, it can be concluded that the diameters of corpus callosum when measured in cadaveric brain specimens and MRI scans, the diameters were more in MRI scans measurement than the cadaveric brain specimens. Thus, future research to find out the deviation in MRI measurement than the actual morphometry of corpus callosum is needed, so that neurosurgeons can plan corpus callosum related surgeries precisely.

\section{REFERENCES}

[1] Ozdemir St, Ercan I, Sevinc S, Guney I, Ocakoglu G, Aslan E, et al. Statistical shape analysis of differences in the shape of the corpus callosum between genders. The Anatomical Record. 2007;290(7):825-30.

[2] Brodal P. The Central Nervous System. Structure and function. Oxford. 2010.

[3] Datta AK. Essentials of Neuroanatomy. Current Books International. 2009.

[4] Gupta T, Singh B, Kapoor K, Gupta M, Kochar S. Corpus callosum morphometry: Comparison of fresh brain, preserved brain and magnetic resonance imaging values. Anatomical Science International. 2008;83(3):162-68.

[5] Goncalves-Ferreira AJ, Herculano-Carvalho M, Melancia JP, Farias JP, Gomes L. Corpus callosum: Microsurgical anatomy and MRI. Surg Radiol Anat. 2001;23(6):409-14.

[6] Bermudez P, Zatorre RJ. Sexual dimorphism in the corpus callosum: Methodological considerations in MRI morphometry. Neuroimage. 2001;13(6 pt 1):1121-30.

[7] Anagnostopoulou S, Mourgela S, Katritsis D. Morphometry of corpus callosum: an anatomical study. Neuroanatomy. 2006;5:20-23. http://citeseerx.ist.psu.edu/ viewdoc/download?doi=10.1.1.140.1177\&rep=rep1\&type=pdf.

[8] Oguz I, Yaxley R, Budin F, Hoogstoel M, Lee J, Maltbie E, et al. Comparison of magnetic resonance imaging in live vs. post mortem rat brains. PLOS ONE. 2013;8(8):01-09.

\section{PARTICULARS OF CONTRIBUTORS:}

1. Assistant Professor, Department of Anatomy, Silchar Medical College and Hospital, Silchar, Assam, India.

2. Professor, Department of Surgery, Gauhati Medical College and Hospital, Guwahati, Assam, India.

3. Assistant Professor, Department of Anatomy, Silchar Medical College and Hospital, Silchar, Assam, India.

4. Demonstrator, Department of Anatomy, Silchar Medical College and Hospital, Silchar, Assam, India

NAME, ADDRESS, E-MAIL ID OF THE CORRESPONDING AUTHOR: Dr. Krishna Kanta Biswas,

Demonstrator, Department of Anatomy, Silchar Medical College and Hospital,

Silchar-788014, Assam, India.
E-mail: prcanatomist@gmail.com
PLAGIARISM CHECKING METHODS: [Nain Het al.]

- Plagiarism X-checker: Jun 04, 2021

- Manual Googling: Sep 27, 2021

- iThenticate Software: Dec 03, 2021 (14\%)
ETYMOLOGY: Author Origin

\section{AUTHOR DECLARATION:}

- Financial or Other Competing Interests: None

- Was Ethics Committee Approval obtained for this study? Yes

- Was informed consent obtained from the subjects involved in the study? Yes

- For any images presented appropriate consent has been obtained from the subjects. Yes
Date of Submission: Jun 03, 2021 Date of Peer Review: Aug 16, 2021 Date of Acceptance: Sep 28, 2021 Date of Publishing: Jan 01, 2022 